\title{
L'aula de noves tecnologies per a les ciències: aplicacions a l'ESO
}

\author{
Joan A. Faus \\ IES Els Alfacs, Sant Carles de la Ràpita \\ jfaus1@gmail.com
}

La física i Química de 4t d'ESO ara es pot estudiar amb l'ajut d'una sèrie d'activitats dissenyades per a ser realitzades amb l'aula de noves tecnologies per a les ciències. Les activitats consisteixen en protocols de pràctiques per als alumnes, protocols amb suggeriments per als professors $i$ presentacions PowerPoint associades a cada pràctica. Hi ha onze activitats. Es poden trobar a la web de l'autor en format pdf $i$ word per tal que el professor puga modificar-ho a voluntat.

\section{EL PER QUÈ DEL TREBALL}

La idea sorgeix a partir de l'arribada de l'aula de noves tecnologies per a les ciències a l'IES Deltebre al llarg del curs 2003-04. És aleshores quan decidim tot el departament de ciències d'aquest centre apuntar-nos al curs per a l'ús didàctic de les aules de noves tecnologies per a les ciències, a l'IES Joaquim Bau de Tortosa impartit per professors del CDECT de les Terres de l'Ebre. Aquest curs, ens va animar a treballar com més aviat millor amb un material que va demostrar ser extremadament atractiu i no tan difícil d'emprar com a priori suposàvem.

Al llarg del curs 2004-05 vaig fer ús de l'aula de noves tecnologies per a les ciències (fig. 1), però no amb alumnes de batxillerat sinó amb alumnes de 4t d'ESO constatant l'enorme atractiu que els suposava treballar amb experimentació assistida per ordinador.

Primer vaig intentar trobar dins la XTEC material per a l'ús d'aquesta aula amb l'ESO, notant l'absència d'una web on el professorat disposés del material organitzat per a l'ESO. El que sí que vaig trobar és el que ja coneixia, l'extraordinari material que el CDECT ha creat perquè els professors puguin preparar pràctiques de batxillerat.

Llavors vaig pensar en l'oportunitat de crear un material semblant per a l'ESO que permetés optimitzar l'ús de l'aula, ja que no sempre estan utilitzats els recursos materials que proposa el Departament d'Ensenyament per falta d'uns materials fàcilment accessibles per Internet, evitant desplaçaments a les seus del CDECT o als CRP.

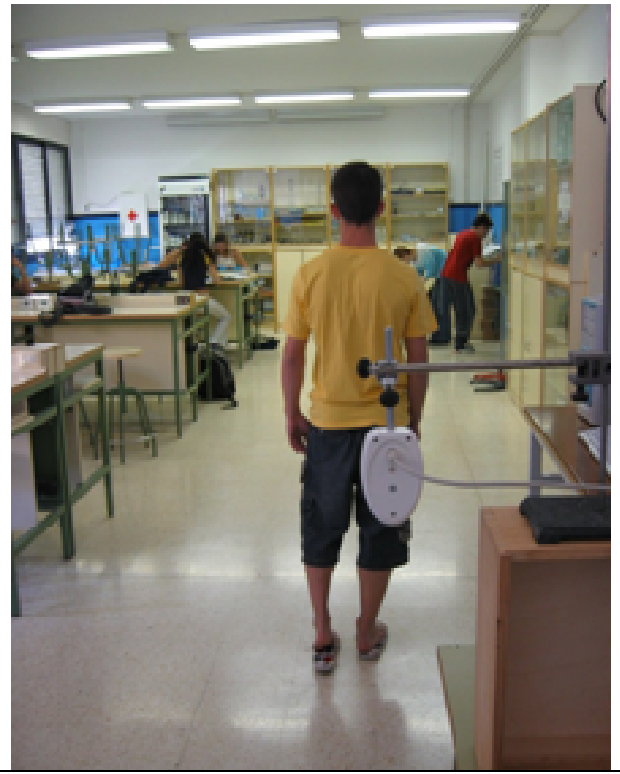

Figura 1: Alumne realitzant una pràctica

He constatat que l'ús de l'aula representa per al professorat una certa temor, ja siga per l'elevat nivell de les pràctiques del CDECT o per la por a canviar de metodologia; però també he constatat la coincidència en els avantatges que representa el seu ús.

Així vaig pensar que si es dinamitzés la seua utilització i es presentaren materials que facilitaren la realització de pràctiques, el seu ús augmentaria.

D'altra banda, com a professor de ciències experimentals, crec que hem d'intentar que els/les nostres alumnes facen l'elecció d'un Batxillerat Cientí- 
fic, cercant nous mètodes d'ensenyament-aprenentatge que modifiquen els interessos del nostre alumnat. Una manera de fer-ho és intentar transmetre els coneixements de forma que l'alumnat accepte la informació científica com rep la informació del món que l'envolta, utilitzant les mateixes eines que utilitza en el seu dia a dia: es a dir, la utilització dels PCs, i les TIC.

\section{TEMA DEL TREBALL}

El que he pretès és crear uns materials seguint l'exemple de les pràctiques de batxillerat del CDECT, amb un període curt de presa de dades i una més llarga anàlisi de les gràfiques obtingudes, unes presentacions multimèdia de cada pràctica per projectar amb un canó de vídeo, una web on facilitar l'accés al material creat i un fòrum on intercanviar experiències i resoldre dubtes.

El material elaborat el podeu trobar en la web http://www.xtec.cat/ -jfaus (fig. 2) i ha estat realitzat en el temps de llicència retribuïda del curs 2005-06. Consisteix en una sèrie de protocols de pràctiques per a alumnes, protocols per a professors i presentacions PowerPoint associades a cada pràctica.

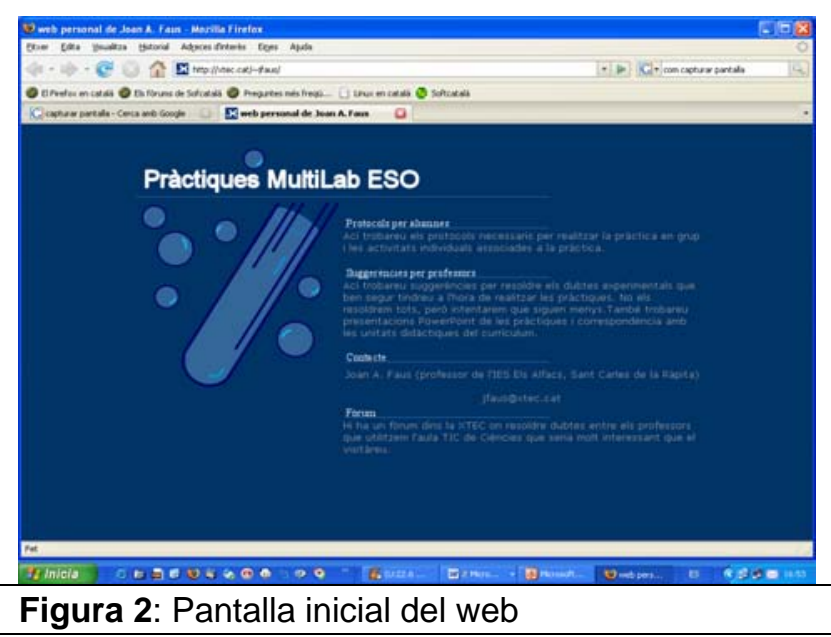

Del currículum de Ciències Experimentals de 4t d'ESO, he escollit els protocols següents:

1) MRU

2) Llei de Hooke

3) Determinació del punt de fusió del p-diclorobenzè

4) Independència de $g$ envers la massa

5) Principi d'Arquímedes

6) Pluja àcida

7) Mescla eutèctica (variació del punt de fusió per crioscòpia)
8) Influència de la temperatura en la velocitat de reacció

9) Efecte hivernacle

10) Pressió hidrostàtica

11) Relació entre la intensitat sonora i la distància

\section{METODOLOGIA DE TREBALL AMB EL MATERIAL CREAT}

Per fer bona l'aplicació d'aquest material cal que s'utilitze, a les hores de desdoblament, de la següent manera:

- La primera sessió es pot realitzar al laboratori o no, depenent de si hi ha canó de projecció de vídeo, ja que s'ha de dedicar a explicar, amb l'ajuda de la presentació PowerPoint, els conceptes que s'estudiaran en la pràctica, la seua realització amb els seus procediments experimentals, els resultats que s'esperen obtenir i, si es desitja, informació ampliada que contextualitza històricament la pràctica.

- La segona sessió s'ha de realitzar a l'aula de noves tecnologies per a les ciències i consisteix en la realització del protocol experimental per part dels alumnes. Per a la correcta realització, el professor disposa en la web d'una sèrie de suggeriments que l'ajudaran davant els possibles dubtes que hi puguen sorgir.

- La tercera sessió s'ha de dedicar a la realització de l'informe de la pràctica amb les activitats que hi ha detallades al protocol de l'alumne (si no és que el professor vol que els alumnes avancen feina a casa i ja porten avançat l'informe) i a la discussió de resultats.

\section{Els protocols de pràctiques}

Els onze protocols que es poden trobar a la web, dins l'apartat Protocols per als alumnes (fig. 3), estan estructurats seguint el model dels protocols del CDECT per tal que els professors acostumats a treballar amb ells troben una continuïtat i no tinguen dificultat en seguir-los. Així doncs consten de les següents parts:

- objectius

- introducció

- material

- procediment experimental

- muntatge de l'experiència

- configuració del programa MultiLab i la consola MultiLogPRO 
- enregistrament de dades

- anàlisi de dades

- qüestionari

- informe

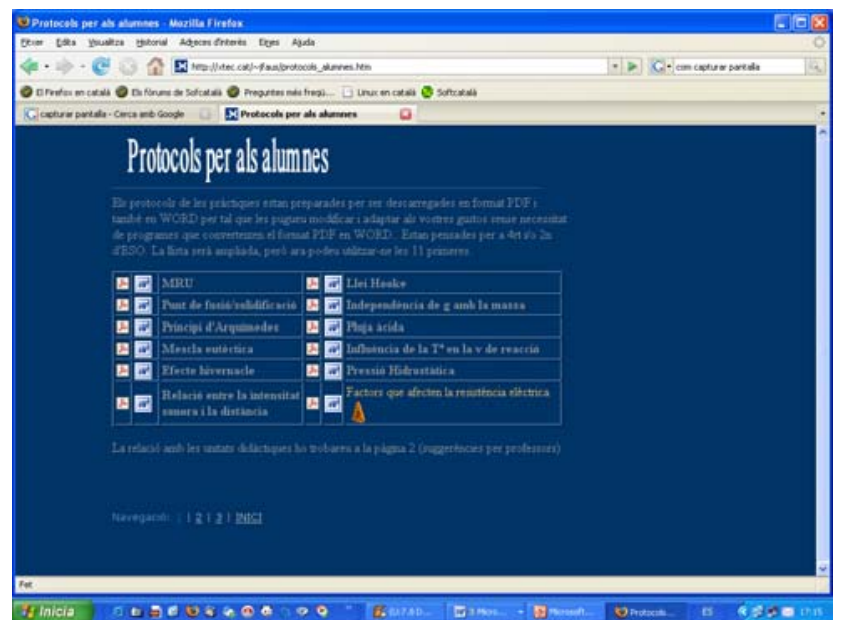

Figura 3: Pantalla inicial dels Protocols per als alumnes.

Igualment, dins l'apartat Suggeriments per a professors (fig. 4), hi ha per a cada pràctica una guia del professor on se l'orienta sobre la ubicació de la pràctica dins del currículum, la temporització, la metodologia didàctica, els possibles problemes tècnics, etc.

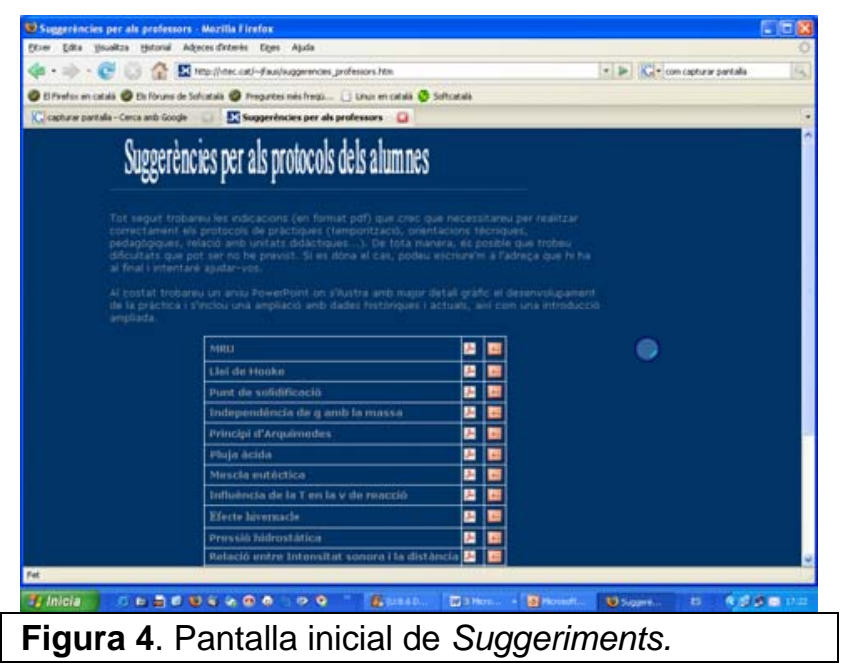

\section{Les presentacions PowerPoint}

Com a novetat respecte al material del CDECT hi he afegit una presentació PowerPoint d'unes 15 diapositives per a cada pràctica. Hi trobareu una introducció teòrica més desenvolupada que als protocols, una explicació gràfica de la realització de la pràctica, i una ampliació de la teoria que inclou una contextualització històrica de la pràctica on es fa esment a la vida i obra del científic de més rellevància dins del tema de la pràctica i/o del científics més importants relacionats amb el tema així com informar de les darreres novetats científiques relacionades amb el tema tractat. Aquestes presentacions les trobareu a la pantalla de Suggeriments per a professors amb una icona PowerPoint:

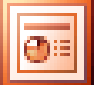

\section{RECURSOS UTILITZATS}

El material s'ha creat a partir del programari MultiLab disponible a les aules de noves tecnologies per a les ciències que hi ha a la majoria dels IES públics. Òbviament, també s'ha utilitzat la consola MultiLogPRO que forma part de l'equipament de l'aula de noves tecnologies, amb tots els sensors que hi porta.

D'altra banda, s'ha utilitzat material disponible a qualsevol laboratori escolar i a qualsevol IES com ara provetes, cintes mètriques, molles, peses, suports, nous, pinces, pilotes, etc. L'únic material més difícil de trobar han estat les barretes quimioluminiscents que es poden comprar en botigues de pesca.

Pel que fa a recursos ofimàtics, s'ha utilitzat el programa Microsoft Word i Adobe Acrobat per crear els protocols i el programa Microsoft PowerPoint per crear les presentacions.

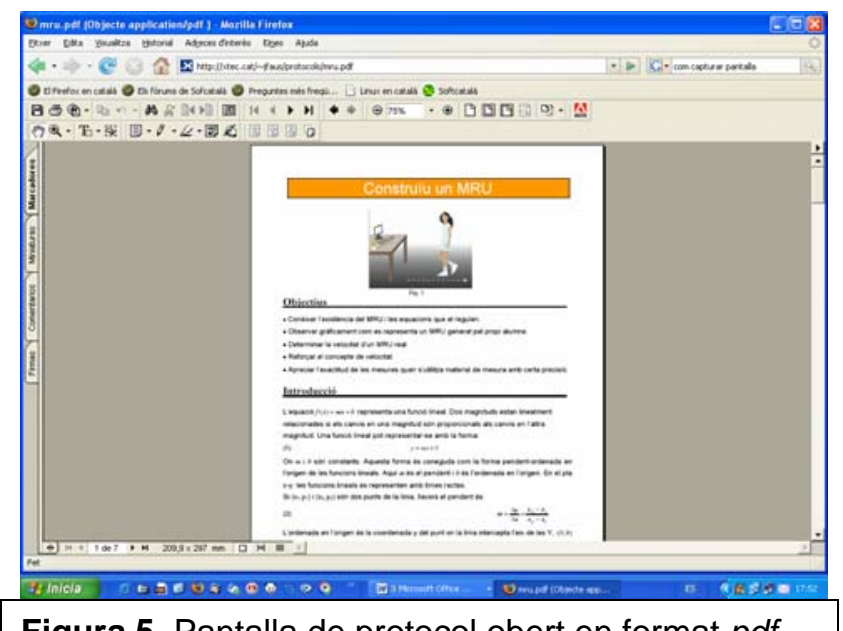

Figura 5. Pantalla de protocol obert en format $p d f$.

El fet de presentar els protocols dels alumnes en word i en pdf (fig. 5) rau en permetre la modificació dels protocols per poder adaptar-los a les necessitats de cada grup d'alumnes; això és fàcil de fer amb word i més difícil en pdf (necessites programari específic). D'altra banda com que ocupa menys es- 
pai un arxiu pdf que un de word (i és més ràpid, doncs, de descarregar) he decidit també presentar els protocols en format $p d f$.

Si cliqueu la icona del format word,

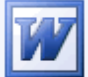

automàticament es descarregarà l'arxiu i s'obrirà el programa Word on apareixerà obert. Per contra si cliqueu la icona del format pdf,

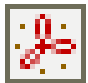

s'obrirà dins del navegador directament el protocol i el podreu llegir i guardar, si convé, en aquest format, però difícilment el podreu modificar.

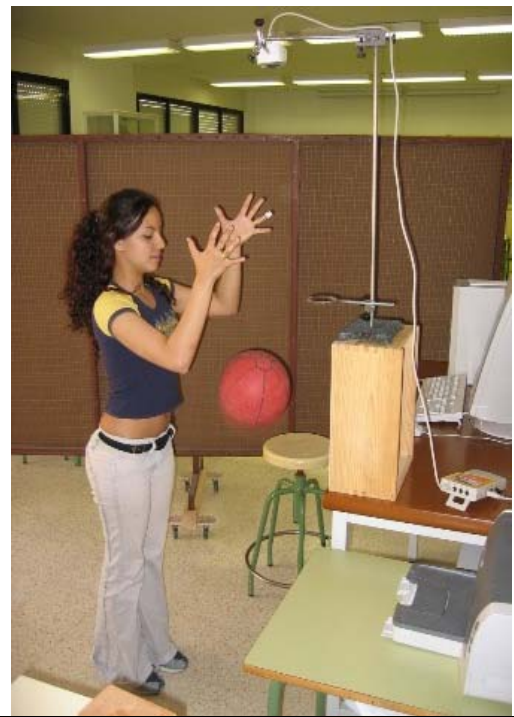

Figura 6. Alumna realitzant la pràctica de la $g$.

\section{CONCLUSIONS}

Com he indicat abans, amb aquests materials he pretès utilitzar tres sessions de desdoblament per cada protocol: una per la preparació de la pràctica amb la presentació PowerPoint, una altra per la realització de la pràctica i finalment, una altra per l'elaboració, anàlisi i discussió del informe de la pràctica. Si he creat un material que permeta utilitzar més eficaçment les hores de desdoblament i l'alumnat mostra més interès pels continguts científics, si el professor troba una eina fàcil alhora que rigorosa per la seua feina, donaré per bo el meu treball.

Durant la llicència d'estudis que ha permès realitzar aquest treball s'han quedat molts protocols inacabats: bé perquè hi sorgien dificultats tècniques insalvables o que per a mi han estat impossibles de solucionar; bé per falta de temps. La feina ha estat engrescadora. Precisament per això han quedat protocols per fer, perquè qualsevol tema em semblava susceptible de ser abordat des de la perspectiva de les TIC. Això no vol dir que en el futur no s'acaben aquests protocols. El treball, doncs, no està finalitzat.

\section{PROPOSTA}

Des d'ací convide als professors/es que estiguen interessats a treballar amb aquests protocols i presentacions que s'animen a modificar-los i a crearne de nous. És per això que propose un contacte via correu electrònic (jfaus1@gmail.com) amb les persones interessades i l'enllaç al Fòrum que de manera molt eficaç gestiona Julián Oro dins l'XTEC, per tal d'intercanviar experiències $i$, si els sembla bé, incloure els nous protocols que creïn en la web de la llicència (http://www.xtec.cat/ -jfaus).

Crec que encara queden molts protocols interessants per fer, ja que no m'ha estat possible en el temps reduït d'una llicència.

Però anime als professor/es de ciències experimentals a seguir en aquest procés de recerca de noves possibilitats que ofereixen les TIC, així com també pretenc personalment completar en els propers anys els protocols que s'han quedat inacabats.

Espere que us siga d'utilitat i moltes gràcies per la vostra visita.

\section{BIBLIOGRAFIA}

Entre altres, s'ha fet ús del següents llibres per elaborar els materials:

CALVET, M. i al. (2003) Curs per a l'ús didàctic de les aules de noves tecnologies per a les Ciències. Materials de Formació. Generalitat de Catalunya. Departament d'Ensenyament.

CALVET, M. (2003). Introducció a l'equip MultiLogPRO $i$ al programa Multilab, dins de Curs per a l'ús didàctic de les aules de noves tecnologies per a les ciències. Departament d'Ensenyament. Generalitat de Catalunya.

NORA, R., AUGUSTO, M. (1998). Enfoque metodológico alternativo para la realización de prácticas de laboratorio. Revista Alambique, 15, p. 99. Editorial Graó, Barcelona.

FERNÀNDEZ, R. i al. (2002). Forces 1. Editorial Vicens Vives, Barcelona.

FONTANET, A. i PASTOR, J.M. (2002). Heli 4: Fisica i Química de $4 t$ d'ESO. Editorial Vicens Vives, Barcelona. 